\title{
Identifying management and disease priorities of Canadian dairy industry stakeholders
}

\author{
C. A. Bauman, ${ }^{* 1}$ H. W. Barkema, $†$ J. Dubuc, $\ddagger$ G. P. Keefe, $\S$ and D. F. Kelton* \\ *Department of Population Medicine, University of Guelph, Guelph, Ontario N1G 2W1, Canada \\ †Department of Production Animal Health, University of Calgary, Calgary, Alberta T2N 1N4, Canada \\ $\ddagger$ Faculté de Médecine Vétérinaire, Université de Montréal, St-Hyacinthe, Québec J2S 7C6, Canada \\ §Department of Health Management, University of Prince Edward Island, Charlottetown, Prince Edward Island, C1A 4P3, Canada
}

\begin{abstract}
The objective of this study was to identify the key management and disease issues affecting the Canadian dairy industry. An online questionnaire (FluidSurveys, http://fluidsurveys.com/) was conducted between March 1 and May 31, 2014. A total of 1,025 responses were received from across Canada of which $68 \%(\mathrm{n}=$ 698) of respondents were dairy producers, and the remaining respondents represented veterinarians, university researchers, government personnel, and other allied industries. Participants were asked to identify their top 3 management and disease priorities from 2 lists offered. Topics were subsequently ranked from highest to lowest using 3 different ranking methods based on points: 5-3-1 ( 5 points for first priority, 3 for second, and 1 for first), 3-2-1, and 1-1-1 (equal ranking). The 5-3-1 point system was selected because it minimized the number of duplicate point scores. Stakeholder groups showed general agreement with the top management issue identified as animal welfare and the number one health concern as lameness. Other areas identified as priorities were reproductive health, antibiotic use, bovine viral diarrhea, and Staphylococcus aureus mastitis with these rankings influenced by region, herd size, and stakeholder group. This is the first national comprehensive assessment of priorities undertaken in the Canadian dairy industry and will assist researchers, policymakers, program developers, and funding agencies make future decisions based on direct industry feedback.
\end{abstract}

Key words: Canada, priorities assessment, management, disease, welfare

\section{INTRODUCTION}

As funding for scientific research and programs has significantly decreased over the last $10 \mathrm{yr}$ in Canada

Received February 19, 2016.

Accepted August 10, 2016.

${ }^{1}$ Corresponding author: cbauman@uoguelph.ca
(Wallace, 2012), competition for available funds has increased. Subjective appeals for funding are no longer acceptable; an evidence-based justification of which issues should be prioritized must be demonstrated (Soriano, 2012). A priorities assessment is a systematic approach of determining priorities through the analysis of pre-existing data (e.g., disease prevalence, resource utilization) if available, the surveying of people who work in or are served by a particular industry, or both (Witkin and Altschuld, 1995). A benefit of including the surveying of stakeholders in the process is that a decision is not made unilaterally by an administrator(s), so the results are reflective of those directly involved in the industry. In addition, it stimulates involvement of different industry players, and the more people involved in the process the more likely attention will be paid to the results (Stevens et al., 2004).

Priority assessments are routinely undertaken in the human health care (Wright et al., 1998; Stevens et al., 2004), educational (Grant, 2002), technology (Rogat, 2013), and scientific (Stein et al., 2005) fields. Priority assessments in the dairy industry to date have limited their focus to specific regions (e.g., one state or province; OACC, 2008; Pereira et al., 2013), one segment of the industry (e.g., organic farms; OACC, 2008), or a limited group of stakeholders (e.g., government personnel; PMMI, 2013). However, with the reduction in available research funds, larger, national, collaborative studies are needed to make efficient use of the money that is available and therefore national priority assessments need to be performed. One example has been the National Animal Health Monitoring System (NAHMS) dairy priorities assessments in the United States, which are undertaken every 5 to $7 \mathrm{yr}$ before their national dairy studies are organized (NAHMS, 1996). Because no assessment has been done of the Canadian dairy industry as a whole at the national level, results of the NAHMS priorities assessment are frequently cited. However, the Canadian supply management system, whereby milk production and price are more stable, and the northern climate could potentially affect the 
prioritization of management and disease issues between the 2 countries.

Therefore, the main purpose of this study was to identify the current issues and concerns in the Canadian dairy industry. The goal was to recruit a wide spectrum of industry stakeholders to prioritize a list of management and animal health/disease issues and to identify if any differences existed regionally, between stakeholder groups or herd sizes.

\section{MATERIALS AND METHODS}

\section{Recruitment}

An online questionnaire was created using survey software by FluidSurveys (http://fluidsurveys.com/). The questionnaire was available online from March 1 until May 1, 2014. Dairy stakeholders that were recruited to complete the questionnaire were in 5 main categories: dairy producers, veterinarians, university researchers (some of whom were also veterinarians but not practicing), government personnel, and other (pharmaceutical representatives, nutritionists, allied industries/organizations, and consultants). Sample size calculation was based on the equation to estimate proportions (Equation 2.4) as per Dohoo et al. (2009) and using a precision of 0.05 , confidence of 0.95 , and a proportion of 0.50 , which represents the proportion of respondents selecting a specific issue as a first priority that yielded the largest variance. This resulted in a target sample size of 363 stakeholders. An approximate sampling frame of $\sim 13,000$ stakeholders (approximately 12,000 producers, 400 veterinarians, 120 university researchers, 200 government personnel, and 200 other representatives) was estimated and the objective was to attempt to contact as many as possible. Recruitment of stakeholders was primarily through electronic media, published magazines, and meetings/conferences to reduce turnaround time, minimize cost, and facilitate the completion of the priority assessment within 90 d. To recruit dairy producers, all provincial marketing boards were asked to distribute the website address to their members during the month of March using any methods available to them that would not violate privacy policies (e.g., link on their websites, distributed via newsletters or e-mail, announcements made at meetings). Articles were placed in the main producer magazines during the months of March and April along with a $1 / 4$ page advertisement that included the website address. Postcards with background information, the website address, and a quick read code were printed and distributed at conferences and meetings, and speakers included the quick read code in any talks given. Nonproducer stakeholders were contacted via e-mail through addresses readily available on the Internet. In the e-mail they were asked to forward the website link to their dairy industry contacts. A Twitter account and Facebook page were created containing relevant information and the website link. Announcements and reminders were tweeted out to followers every 2 wk by the study group and by various dairy organizations. Paper versions of the questionnaire were provided upon request. All individuals were informed about the nature of the study and provided digital informed consent, and responses were collected anonymously.

\section{Questionnaire}

The survey was structured in 3 parts, which covered (1) demographics, (2) identification of management issues, and (3) identification of diseases, disorders, or pathogens. The content of the survey was developed by 4 dairy researchers from 4 veterinary/agricultural schools located across the country (one from Western Canada, one from Ontario, one from Québec, and one from Eastern Canada). Previous NAHMS study priorities assessments were used as a guide in the development (Jason Lombard, USDA-Animal and Plant Health Inspection Service, Fort Collins, CO; personal communication), but modified for the Canadian industry. The questionnaire was initially constructed in English, translated to French, and then reviewed by 3 dairy researchers whose first language was French (Supplemental file; http://dx.doi.org/10.3168/jds.2016-11057). Prior to distribution, the questionnaire was pretested on 20 purposively selected dairy stakeholders, including dairy producers, veterinarians, and government personnel who spoke either English or French. Any questions that were unclear were revised. No identifying information was requested from respondents other than province of residence (drop-down menu), occupation (drop-down menu), and herd size (fill in the blank) if they were a dairy producer. Two main questions were then included that involved closed-ended questions in a matrix style. For the first question, respondents were asked to read a list of 29 management issues (e.g., biosecurity, manure management, antimicrobial use, nutrition, and water quality) and identify their top 3 priorities for the dairy industry. Issues were listed in alphabetic order because the individuals who pre-tested a randomized list indicated that the randomization made it frustrating and confusing. The listed issues were derived from a previous NAHMS needs assessment survey with items specific to the Canadian industry added and those items that were not relevant to Canada removed. Respondents identified their first priority and were then given the option of elaborating in more detail in an open-ended question allowing for answers up to 10 lines in length. The 
process was repeated for the second and third priority. The second question asked respondents to identify their top 3 priorities from a list of 27 animal health/ infectious disease concerns (e.g., lameness, abortions, parasites, and respiratory disease). For both questions, the respondent was given the option of an "other" category if they felt an issue was not listed. These options were available at all times for a respondent to go back and change their choice or modify their entry in the open-ended textbox. Respondents were not given the option to list more than 3 priorities, but could rank fewer than 3 items as priorities. For a questionnaire to be considered complete and included in the analysis, a respondent had to provide digital informed consent and identify their province of residence, occupation, and rank at least one priority. In the questionnaire software platform, these were set as required elements, meaning a respondent could not skip these elements, to minimize missing data. Otherwise, no adjustments were made for missing data.

The University of Guelph's Research Ethics Board provided review and approval for the study (REB \#13OC003), and a consent form, along with the University of Guelph's research ethics board contact information, was provided to those asked to complete the questionnaire. All participants were provided with the mailing address, phone number, and e-mail address of the evaluator in case questions arose about the questionnaire or the overall research study.

\section{Data Analyses}

All questionnaire data were exported from FluidSurveys and stored in Excel 2013 (Microsoft Corporation, Redmond, WA). Descriptive statistics were derived using Stata version 12.1 (StataCorp, College Station, TX). For all analyses, a $P$-value $<0.05$ was considered significant. To assess if listing the question responses in alphabetic order had any influence on how many respondents chose the answer, the issues were listed alphabetically against the ranking of issues by number of respondents (all stakeholder groups) that chose that issue as one of their top 3 priorities. These 2 variables were then assessed using Spearman's rank-order coefficient. This assessment was performed separately for management issues and disease issues. To determine if a difference was present in the proportion of respondents who answered the management versus the disease issues question, the 2-sample z-test of proportions was used.

To determine the ranking of the priorities, each management, disease, and incentive issue highlighted as a first priority by a respondent was assigned 5 points, second priorities received 3 points, and third priorities received 1 point. Points for each issue were summed, and the issues were then ranked from highest to lowest based on their total score. To evaluate the influence of points assigned on the ranking results, the rankings of the uncategorized data (not sorted by region, herd size, or occupation) were compared with those obtained using a 3-2-1 point-system (3 points for a first priority, 2 points for a second, and so on) and equal points assigned whether the item was listed as a first, second, or third priority. These were compared visually and using Spearman's rank-order coefficient.

\section{RESULTS}

\section{Respondent Demographics}

In the 8-wk period, 1,080 respondents accessed and filled out at least part of the questionnaire. A total of 55 questionnaires were excluded due to duplication, missing occupation or province of residence, or if they did not identify at least 1 management or disease priority, leaving 1,025 responses (95\% completion rate) that were included in the analyses. The response rate was not directly quantifiable; however, if we assume that every potential stakeholder from the estimated sampling frame was made aware of the survey through one or more of the forms of notification, the response rate would be $7.9 \%(1,025 / 13,000)$.

Of total respondents, 698 were dairy producers. Mean herd size was 118 cows, based on the data of 592 producers as 106 did not state their herd size. Occupation was categorized into 5 main groups: dairy producers $(\mathrm{n}=698 ; 68 \%)$, veterinary practitioners (n $=70 ; 7 \%)$, university personnel $(\mathrm{n}=64 ; 6 \%)$, government industry representatives $(\mathrm{n}=56 ; 5 \%)$, and others $(\mathrm{n}=137 ; 13 \%$; Figure 1$)$. Although many university personnel were also veterinarians, their responses were only included once, under the category of universities. Others consisted predominantly of nutritionists $(\mathrm{n}=$ 38 ), allied industry/pharmaceutical company representatives $(\mathrm{n}=27)$, animal welfare organizations $(\mathrm{n}=10)$, and hoof trimmers $(\mathrm{n}=11)$. All 10 provinces were well represented, with a range of total respondents from 9 in New Brunswick to 366 in Québec (Figure 1). The percentage of producer respondents as a percentage of total farms in a province (based on 2015 data from Canadian Dairy Information Centre) was on average $5 \%(698 / 11,962)$ with a median of $15 \%$, ranging from $3 \%$ in New Brunswick to $59 \%$ in Newfoundland.

\section{Management Issues}

All 5 occupation groups identified animal welfare as the top priority management issue (Table 1). Produc- 


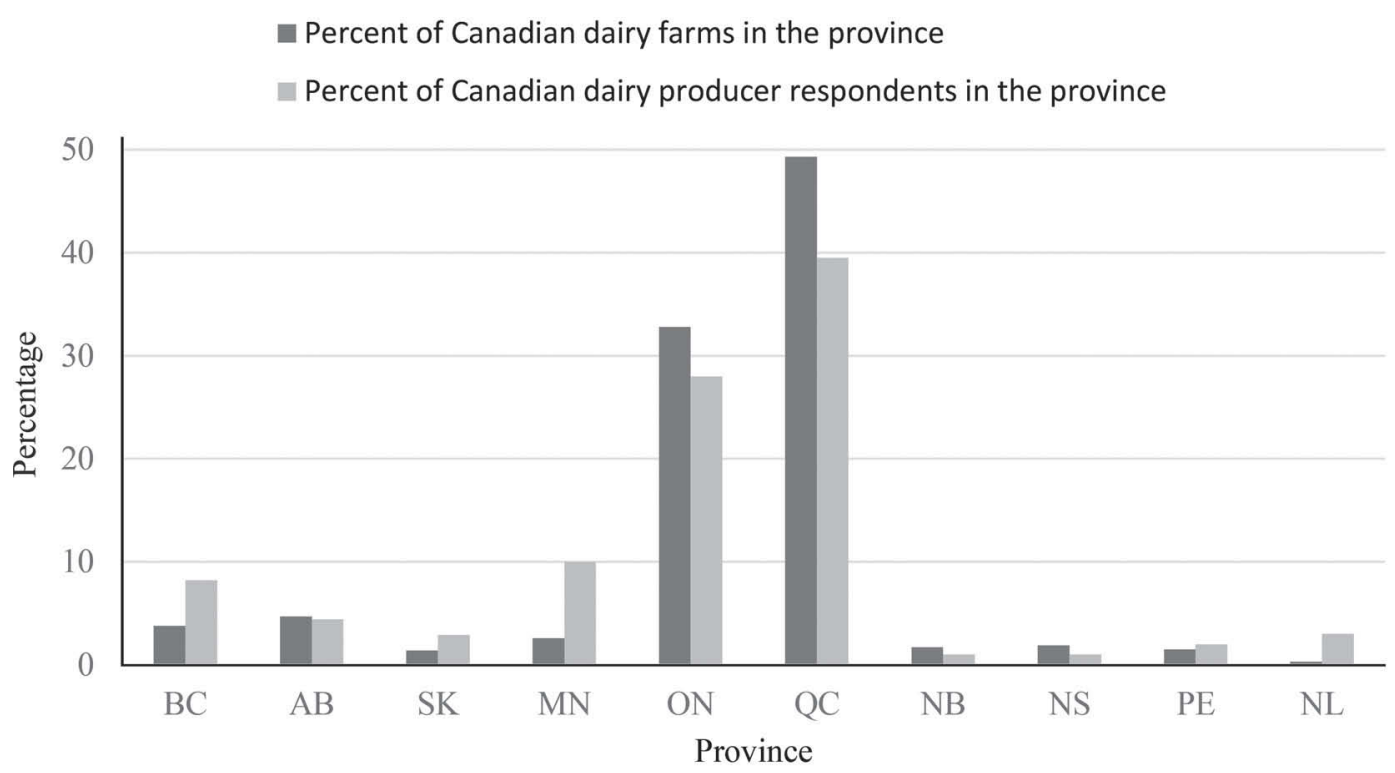

Figure 1. Percentage of dairy producers per province $(\mathrm{n}=11,962)$ relative to the percentage of dairy producers per province who completed the 2014 Canadian Dairy Study Priorities Assessment $(\mathrm{n}=698)$. BC = British Columbia; AB = Alberta; SK = Saskatchewan; MN = Manitoba; $\mathrm{ON}=$ Ontario; $\mathrm{QC}=$ Québec; $\mathrm{NB}=$ New Brunswick; NS = Nova Scotia; PE = Prince Edward Island; NL = Newfoundland.

ers ranked reproductive health second (third by government) and costs of disease third (fifth by others). Antimicrobial use was the second priority of veterinarians, university researchers, and government personnel, whereas universities and government respondents listed biosecurity as their third and fourth priority, respectively. Nineteen respondents prioritized alternative management issues to those offered by selecting the other category and filling in the blank provided. In total, they identified 8 additional topics, which consisted of costs of production (3 respondents), sustainability (4), public perception (2), genetic improvement (1), market growth (4), environment (2), excessive paperwork and program requirements (2), and worker availability (1). Of all respondents, $99.5 \%$ answered the first question and identified at least one management priority. For this question, $84.7 \%$ identified 3 priorities, $12.3 \%$ identified 2 , and $2.5 \%$ only identified 1 (all of which were a first priority).

Spearman's rank-order coefficient $(\rho)$ used to assess the dependence between the alphabetic order and the overall number of stakeholders choosing a management issue as one of their 3 priorities was $0.101(P=0.63)$, indicating the 2 rankings were independent of one another. The influence of the point system on the overall ranking outcomes was negligible for the management issues. For all point systems, animal welfare and reproductive issues were ranked first and second. The next 3 issues (lameness, feed costs, and udder health) always remained in the top 5 , but their respective rankings were different for each system. The remaining 24 issues were essentially ranked the same with no issue ever moving more than 1 position up or down the list. However, an increase in the gap occurred between issues as heavier weighting was placed on the first and second priorities (i.e., 3-2-1 and 5-3-1 point systems). Overall, this points difference resulted in fewer duplicates or issues having the same point score. With the 1-1-1 ranking, 6 pairs of management issues tied with the same score; in the 3-2-1 system only 2 pairs tied, with one triplicate ( 3 issues with the same score), whereas the 5-3-1 system had no issues tied with the same point total (uncategorized data). Some ties still occurred with the 5-3-1 scoring when the data were further categorized by region and occupation; however, the number was again reduced from the other scoring systems. The increased spacing in point scores also resulted in greater spacing between first and second priorities (gap increased from 66 to 175 to 284 ), the fifth and sixth (1 to 4 to 6 ), and the 10th and 11th (4 to 6 to 8 ). Spearman's coefficient for each of the ranking comparisons was 5-3-1 compared with $3-2-1(\rho=0.988 ; P<0.0001), 5-3-1$ to $1-1-1(\rho=0.992 ; P<0.0001)$, and $3-2-1$ to $1-1-1(\rho=$ $0.996 ; P<0.0001)$.

Producer rankings were subsequently categorized by the region in Canada that they resided (Eastern provinces, Québec, Ontario, Western provinces) and the top 5 priorities by region identified (Table 2 ). Six priorities appeared that were not previously listed as a top 5 priority when producers were analyzed as a group: food 
Table 1. Management topics prioritized in the 2014 Canadian Dairy Study Priorities Assessment by the occupation of respondent

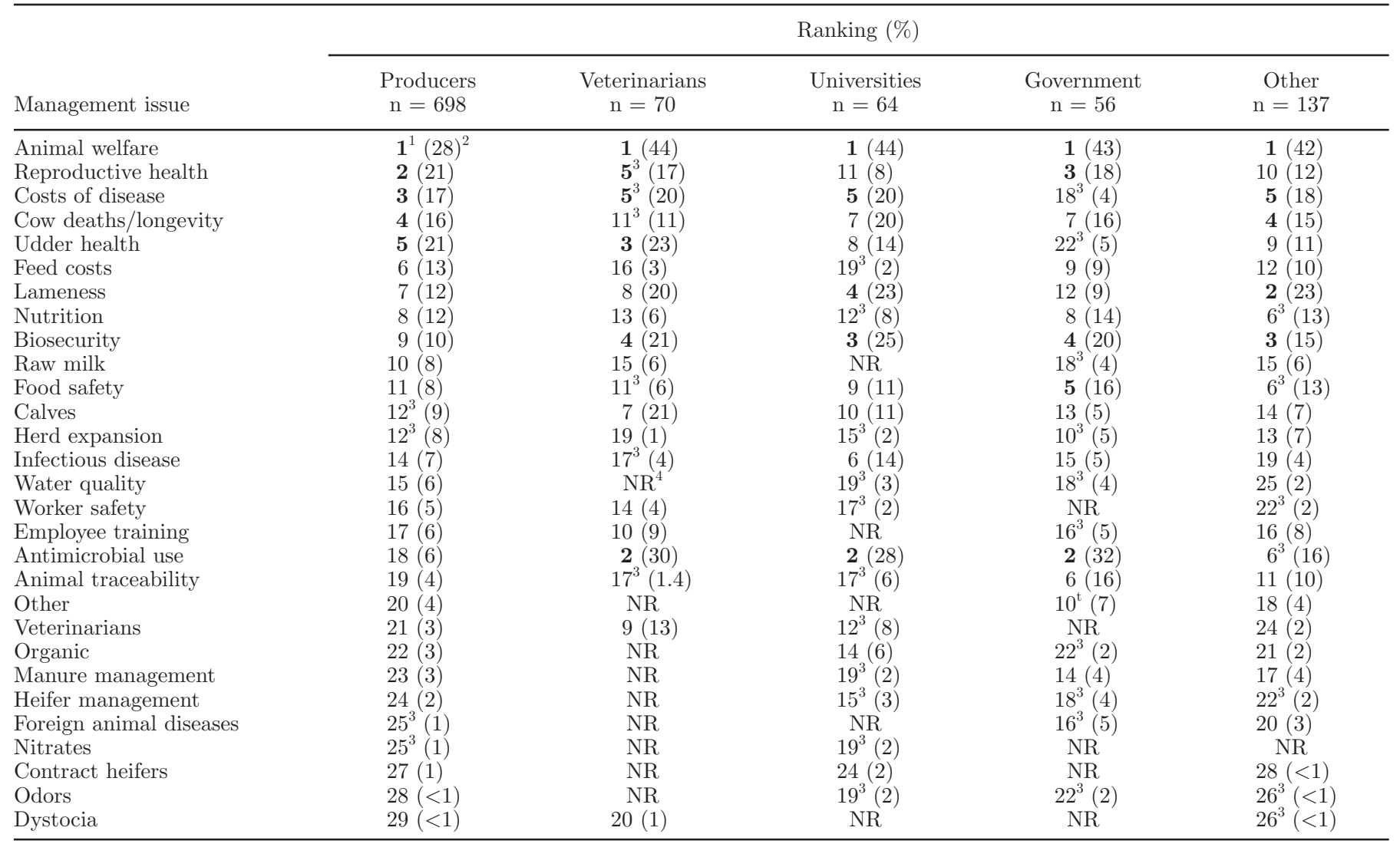

${ }^{1}$ Numbers in bold represent a top 5 priority for that stakeholder group.

${ }^{2}$ Percentage of stakeholders listing this priority as one of their top 3 priorities; totals may sum to greater than $100 \%$ as stakeholders had the option of choosing a maximum of 3 priorities and some percentages may be higher for lower ranking issues as more people may have chosen the issue, but ranked it lower as a second or third priority.

${ }^{3}$ Tied with another management topic for total points and therefore same ranking.

${ }^{4} \mathrm{NR}=$ not ranked, because no one in this occupation selected this topic to be a priority.

safety, feed costs, herd expansion, lameness, biosecurity, and nutrition. In addition, the top 5 priorities were calculated for different herd sizes of adult cows: small (1-100), medium (101-300), and large (>300; Table 3). Herd expansion, raw milk, and employee training were unique issues identified among the top 5 priorities of large herds.

\section{Disease Issues}

With respect to health and disease concerns for the dairy industry, all 5 occupations agreed on lameness as the number 1 priority (Table 4). Staphylococcus aureus mastitis was the second-ranked priority for producers and veterinarians (fourth by others and fifth by universities), whereas the third priority for producers and university members was calf diarrhea (fourth by veterinarians and government respondents). Bovine viral diarrhea (BVD) was the fourth overall choice for universities, and fifth priority for others. Five additional health issues were identified by 5 respondents who selected the other category and filled in the blank provided. They consisted of Haemophilus, ketosis, milk fever, dystocia, and displaced abomasum. Although health and disease priorities were analyzed by producer region and herd size in a similar manner to the management priorities, the only new priorities that appeared in the top 5 were Johne's disease in small and medium herds, BVD in the Western provinces, and bovine leukosis in the Eastern provinces. Of all respondents, $81.4 \%$ answered the second question and identified at least one disease priority, which was significantly lower than the number who responded to the first question ( $\mathrm{z}$ $=13.9 ; P<0.0001$ ). For this question, $83.5 \%$ identified 3 priorities, $10.4 \%$ identified 2 , and $3.7 \%$ only identified 1 (all of which were a first priority).

Spearman's rank-order coefficient $(\rho)$ to assess the dependence between the alphabetic order and the rank- 
DAIRY INDUSTRY TODAY
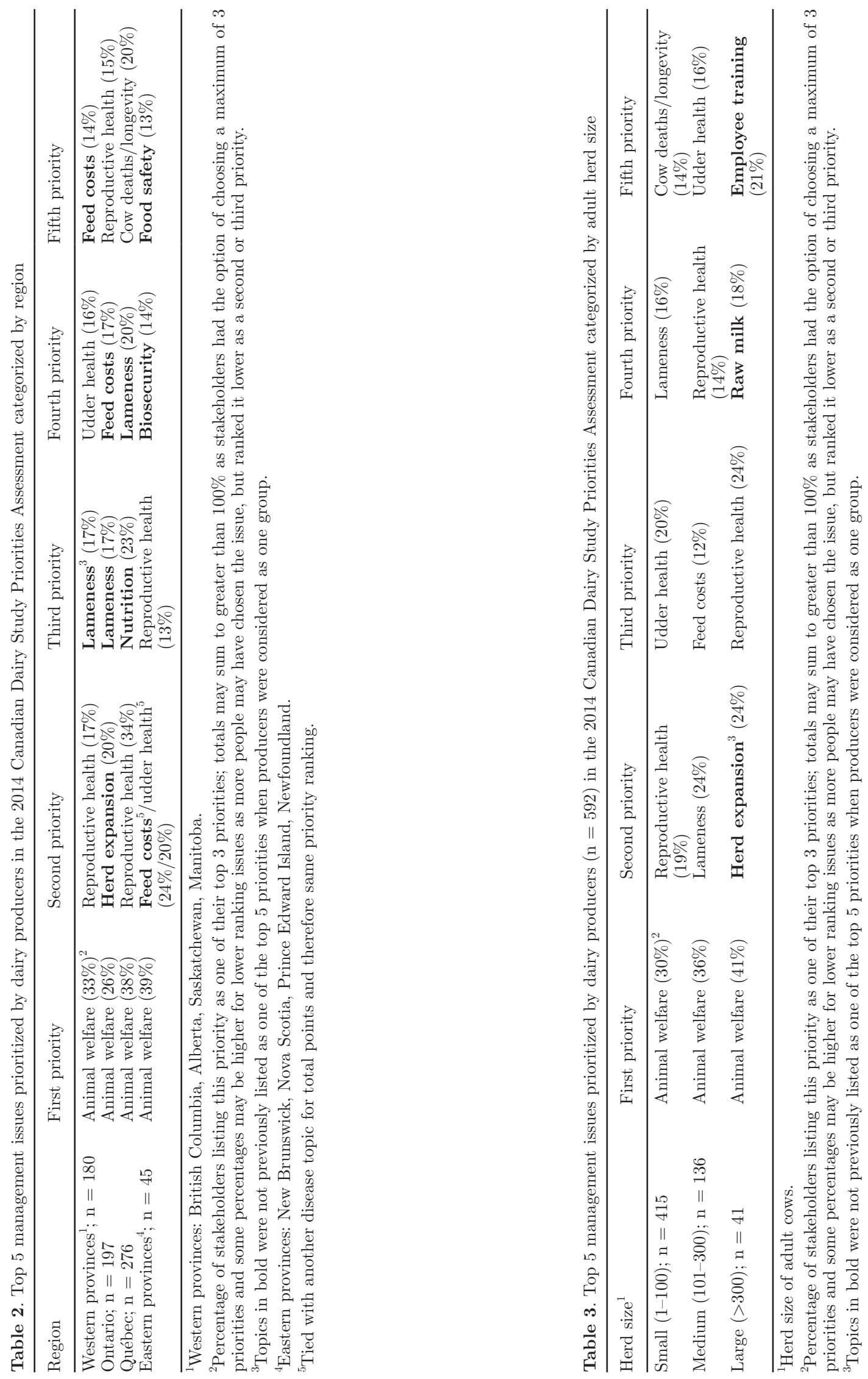
Table 4. Disease topics prioritized in the 2014 Canadian Dairy Study Priorities Assessment by the occupation of respondent $(\mathrm{n}=1,025)$

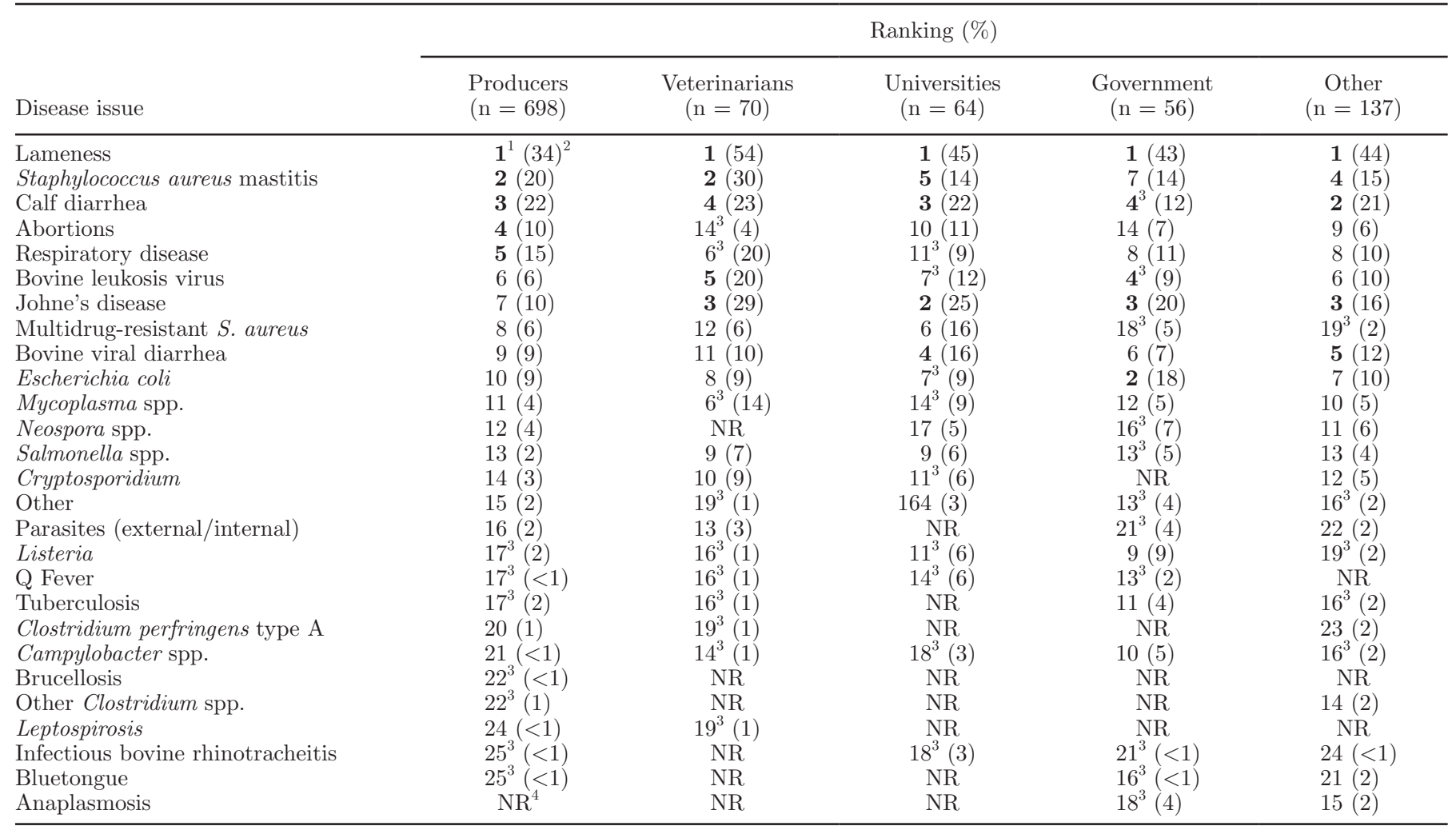

${ }^{1}$ Topics in bold represent the top 5 priorities for that stakeholder group.

${ }^{2}$ Percentage of stakeholders listing this priority as one of their top 3 priorities, totals may sum to greater than $100 \%$ as stakeholders had the option of choosing a maximum of 3 priorities and some percentages may be higher for lower ranking issues as more people may have chosen it, but ranked it lower as a second or third priority.

${ }^{3}$ Tied with another disease topic for total points and therefore same ranking.

${ }^{4} \mathrm{NR}=$ not ranked, because no one in this occupation selected this topic to be a priority.

ing determined by the number of producers choosing a disease issue as one of their 3 priorities was $-0.193(P$ $=0.33$ ), indicating that the 2 rankings were independent of one another. The influence of the point system on the overall ranking for the disease issues was also negligible. For all point systems, lameness was ranked first. The next 4 issues ( $S$. aureus, calf diarrhea, respiratory disease, and Johne's disease) all remained in the top 5 listing, but rearranged their rankings with each system. The remaining 22 issues were essentially the same with no issue ever moving more than one position up or down the list. Similar to the management issues, the number of disease issues that tied with their points score decreased as the point system was weighted to the first and second priorities (e.g., 1-1-1 had 4 ties, 3-2-1 had 2 ties, and 5-3-1 had no ties), and the point difference between the first and second priorities ( 82 to 234 to 386 ), fifth and sixth (30 to 50 to 170), and the 10th and 11th (14 to 26 to 44 ) also increased in a similar fashion. Spearman's coefficient for each of the ranking comparisons was 5-3-1 compared with 3-2-1 ( $\rho=0.993$;
$P<0.0001), 5-3-1$ to $1-1-1(\rho=0.992 ; P<0.0001)$, and $3-2-1$ to $1-1-1(\rho=0.999 ; P<0.0001)$.

\section{DISCUSSION}

To achieve its objectives, a priorities assessment should be as representative as possible of the opinions of those directly involved in the industry. In the context of the Canadian dairy industry, this necessitates a combination of geographic and stakeholder representation. Canada is geographically diverse and the dairy industry varies by province with respect to number of farms, herd size, infectious disease concerns, housing types, milking systems, and feed availability. To feel confident in the results of the priorities assessment, it was important to obtain a balanced response from producers in all provinces. As demonstrated in Figure 1, it was reassuring that all provinces were represented by at least 9 producers and that responses were distributed across the country in relative proportion to the number of farms in that province (median $\sim 15 \%$ ). 
The priorities assessment could have been limited to surveying only producers for feedback, but as the third largest agricultural industry in Canada (Canadian Dairy Information Centre, 2015), the dairy industry has many other stakeholders. The inclusion of these auxiliary stakeholders allowed for the expression of feedback by those slightly removed from day to day farming, but with perhaps a broader perspective on the industry. The additional feedback gathered from policy makers, such as government personnel, and service providers such as veterinarians, hoof trimmers, dairy organizations, and pharmaceutical companies, maximized the recruitment of opinions, but had the potential to complicate the process by producing results that conflicted with one another. The results were reported separately for each stakeholder group: producers, veterinarians, universities, government, and others, and it was encouraging, even surprising, to see the extent of agreement that occurred. All 5 respondent groups identified animal welfare as the top management priority and lameness as the top health concern. Reproductive health, costs of disease, antimicrobial use, biosecurity, S. aureus mastitis, calf diarrhea, and BVD were all top 5 priorities for at least 2 of the groups.

Some minor regional differences were found in rankings of management issues for producers. Herd expansion was listed as a top 5 priority only in Ontario, whereas biosecurity and food safety only appeared in the top 5 rankings in the Eastern provinces. In addition, large herds $(\mathrm{n}=41)$ identified some unique issues that did not appear as priorities for medium and small herds: herd expansion, raw milk, and employee training. While these results highlight the importance of getting respondents from all regions of the country and all sectors of the industry, overall producers are in relative agreement with respect to both management and health concerns.

In the most recent NAHMS priorities assessment (2014) for the US dairy industry, animal welfare and lameness were also listed as the number 1 priorities overall (personal communication, Jason Lombard, USDA-Animal and Plant Health Inspection Service, Fort Collins, CO). Additional overlapping management (e.g., udder health, reproduction, costs of disease) and disease topics (e.g., calf diarrhea, respiratory disease, BVD, Escherichia coli, S. aureus) were identified, however, with some variation in the order of their ranking. In Ireland in 2010, dairy stakeholders and producers prioritized biosecure and nonbiosecure health priorities (More et al., 2010). Respondents identified BVD, Johne's disease, and infectious bovine rhinotracheitis as their top 3 biosecurity health concerns and udder health, calf diarrhea, fertility, and lameness as their top 4 nonbiosecurity health concerns (More et al., 2010), which are consistent with the Canadian and US findings. Overall, published priorities for the dairy industry are lacking.

One limitation of our priorities assessment was the fact that the questionnaire was offered online and promoted mainly through electronic media (websites, e-mails, and Twitter). Therefore, the results derived from the process are excluding the views of individuals or groups without Internet access or without Internet access of sufficient speed to complete the questionnaire online. Statistics Canada has previously reported that $56 \%$ of Canadian farmers use Internet for business, and $44 \%$ have access to high-speed Internet (Statistics Canada, 2011). Notwithstanding the issue of Internet access, the questionnaire may also be more representative of the views of an age group or culture that is more comfortable with communicating via computers and cell phones. Priorities chosen by this group may therefore be influenced by issues circulating on dairy websites and other forms of social media.

Offering the questionnaire online likely influenced our response percentage as well. Response rates for e-mailed questionnaires with no follow-up have been estimated to be 25 to $30 \%$ (Cook et al., 2000), which is historically less than traditional methods (e.g., telephone, mail) of 40 to $50 \%$ (Kerlinger, 1986). In the current study, $\sim 10$ to $20 \%$ of potential stakeholders may have received the link for the questionnaire web address directly by e-mail with the remainder notified through other forms of media that would require more effort on behalf of the respondent to participate. Therefore, it would be expected that the response percentage in this study $(7.9 \%)$ would be less than the aforementioned 25 to $30 \%$. However, it is unlikely that all potential stakeholders identified by this study were reached by the invitation to participate, and because only $\sim 50 \%$ of producers may have had sufficient Internet access to complete it online, a more realistic response rate is probably closer to 15 to $20 \%(1,025 / 6,500)$ or higher. Although it would be ideal to have a higher number of respondents, 1,025 exceeded expectations and our target sample size of 363 and is higher than the number of stakeholders used in other published literature $(\mathrm{n}=$ 85, More et al., 2010; $\mathrm{n}=183$, Pereira et al., 2013).

Another limitation of this priority assessment was the method of presentation of the potential responses to the questions within the questionnaire. Because the issues to be prioritized were listed alphabetically as opposed to offering the issues in a randomly generated order, it could be argued that those issues starting with $\mathrm{a}, \mathrm{b}$, or c would be chosen more frequently. However, during pre-testing, participants indicated that a randomized list was difficult to move through logistically. In addition, the statistical assessment of independence 
for each set of issues, supports the belief that the alphabetic order is independent of the number of producers choosing that issue as one of their priorities.

Overall, it does not appear that the point-system chosen, 5-3-1, heavily influenced the ranking of management or disease issues either. Very minor changes in rankings occurred, but there was no effect on the issues listed within the top 5 or top 10 as a group. Although weighting of responses is always a subjective process and no method can be statistically justified, in this study, the preferred method was the 5-3-1 point system. The heavier weighting on the first and second priorities helped to spread out the point scores to minimize the number of issues sharing the same score and provide greater delineation between the first, fifth, and tenth priorities, which were the important cut-points used to report the data. In addition, using the 5-3-1 point system allowed comparability to the previous NAHMS assessment. Last, although a significant decrease occurred in responses for the second question (disease issues) in comparison to the first, the number of respondents was still quite high $(\mathrm{n}=834)$ and the distribution of priorities identified per question was very similar. Therefore, it is unlikely to have had a large influence on the results obtained.

Although priorities assessments help ensure that decisions are evidence based and not arbitrary choices, the results must still be interpreted carefully. Results may be contextual and simply reflect trends that are currently on the minds of those surveyed. For example, in Canada in the last $6 \mathrm{yr}$ the Codes of Practice for the care and handling of farm animals was recently published (NFACC, 2009), the development of national animal care assessment programs was developed (NFACC, 2014) and piloted (NFACC, 2015), and the dairy industry has undertaken another initiative called ProAction, which is an industry-led integration of existing quality control programs (biosecurity, food safety, livestock traceability, milk quality, environment, and animal welfare) into one national framework (DFC, 2014). The extensive consultation over the years in the development of these codes, assessment programs, and the ProAction initiative have likely kept the topics of animal welfare, biosecurity, antimicrobial use, and food safety foremost in the minds of many dairy stakeholders and may explain their high ranking in the priorities assessment.

\section{CONCLUSIONS}

This is the first national comprehensive assessment of priorities undertaken in the Canadian dairy industry. The top management priority identified by all stakeholders was animal welfare and the top health issue prioritized was lameness. Although general agreement was found on the remaining top 4 priorities, regional and herd-level differences do exist. Based on the high number of responses that represented all stakeholder groups and regions of the industry, this priorities assessment provides the evidence needed by researchers, funding agencies, program developers and policy makers to maximize the effective and efficient use of resources.

\section{ACKNOWLEDGMENTS}

This study was supported by the Dairy Cluster 2 Research Program through the Canadian Agri-Science Clusters Initiative (Dairy Farmers of Canada, Agriculture and Agri-Food Canada, Canadian Dairy Commission, and Natural Sciences and Engineering Research Council). We greatly appreciate the advice and encouragement provided by Jason E. Lombard (USDA-Plant and Animal Health Inspection Service, Fort Collins, $\mathrm{CO}$ ) and the support of all the Canadian dairy stakeholders that participated in this project.

\section{REFERENCES}

Canadian Dairy Information Centre. 2015. Dairy Farming in Canada. Accessed May 18, 2016. http://www.dairyinfo.gc.ca/index_e. php?s1=dff-fcil\#farm.

Cook, C., F. Heath, and R. L. Thompson. 2000. A meta-analysis of response rates in web- or internet-based surveys. Educ. Psychol. Meas. 60:821-836.

DFC (Dairy Farmers of Canada). 2014. ProAction ${ }^{\mathrm{TM}}$. Leading the way for sustainable dairy farming. Accessed May 18, 2016. http://www.google.ca/url?sa =t\&rct $=j \& q=\&$ esrc $=$ s\&source $=$ web\&cd = $3 \&$ ved $=0 \mathrm{CCkQFjAC} \& \mathrm{url}=\mathrm{http} \% 3 \mathrm{~A} \% 2 \mathrm{~F} \% 2 \mathrm{Fwww}$. dairyfarmers.ca $\% 2$ Fcontent $\% 2$ Fdownload $\% 2$ F $2204 \% 2$ F $31162 \%$ 2 Fversion $\% 2$ F $2 \% 2$ Ffile\%2FDFC769_proAction_Report_LR14. pdf\&ei=65fjVITeCYGNyASQlYGYCg\&usg=AFQjCNGRSD4_ Uvjn3hUDo1bhQ2Cp398W-A\&bvm=bv.85970519,d.aWw.

Dohoo, I., S. W. Martin, and H. Stryhn. 2009. Veterinary Epidemiologic Research. 2nd ed. VER Inc., Charlottetown, PEI, Canada.

Grant, J. 2002. Learning needs assessment: Assessing the need. BMJ 324:156-159.

Kerlinger, F. N. 1986. Foundations of Behavioral Research. 3rd ed. Holt, Rinehart \& Winston, New York, NY.

More, S. J., K. McKenzie, J. O'Flaherty, M. L. Doherty, A. R. Cromie, and M. J. Magan. 2010. Setting priorities for non-regulatory animal health in Ireland: Results from an expert Policy Delphi study and a farmer priority identification survey. Prev. Vet. Med. 95:198-207.

NAHMS (National Animal Health Monitoring System). 1996. Dairy '96 needs assessment. Accessed May 18, 2016. http://www.aphis. usda.gov/animal_health/nahms/dairy/downloads/dairy96/ Dairy96_is_NeedsAssess.pdf.

NFACC (National Farm Animal Care Council). 2009. Code of practice for the care and handling of dairy cattle. Accessed May 18, 2016. https://www.nfacc.ca/codes-of-practice/dairy-cattle.

NFACC (National Farm Animal Care Council). 2015. Test pilot of the animal care assessment framework. Accessed May 18, 2016. https://www.nfacc.ca/pilot.

NFACC (National Farm Animal Care Council). 2014. Animal care assessment framework, dairy test pilot summary. Accessed May 18, 2016. https://www.nfacc.ca/resources/assessment/pilot/NFACC_ ACAP_summary.pdf. 
OACC (Organic Agriculture Centre of Canada). 2008. Research needs assessment of British Columbia organic farmers. Accessed May 18, 2016. http://www.dal.ca/content/dam/dalhousie/pdf/faculty/ agriculture/oacc/en/research-priorities/Canadian_Organic_ Research_Needs_Survey_BC_2008.pdf.

Pereira, A. B., A. F. Brito, L. L. Townson, and D. H. Townson. 2013. Assessing the research and education needs of the organic dairy industry in the northeastern United States. J. Dairy Sci. 96:73407348 .

PMMI (The Association for Packaging and Processing Technologies). 2013. Executive summary and industry perspective. Accessed May 18, 2016. http://www.pmmi.org/files/Research/ExecutiveSummar ies/2013DairyExecSummary.pdf.

Rogat, J. 2013. Technology needs assessment (TNA) project. Accessed May 18, 2016. http://www.un.org/en/ga/president/67/issues/ technology/jorge_rogat.pdf.

Soriano, F. I. 2012. Conducting needs assessments: A multidisciplinary approach. SAGE Publications, Thousand Oaks, CA.

Statistics Canada. 2011. Snapshot of Canadian agriculture. Accessed May 18, 2016. http://www.statcan.gc.ca/pub/95-640-x/2011001/ p1/p1-00-eng.htm.
Stein, L., B. Beavis, D. Gessler, S. Rhee, D. Rokhsar, D. Main, L. Mueller, E. Huala, and C. Lawrence. 2005. Plant biology databases: A needs assessment. Accessed May 18, 2016. http://archive. gramene.org/resources/plant_databases.pdf.

Stevens, A., J. Raftery, and J. Mant. 2004. An introduction to HCNA: The epidemiological approach to health care needs assessment. Pages 7-14 in Health Care Needs Assessment: The Epidemiologically Based Needs Assessment Reviews. First series, 2nd ed., vol. 1. A. Stevens, J. Raferty, J. Mant, and S. Simpson, ed. Radcliffe Publishing, Oxford, UK

Wallace, A. 2012. Government's cuts to research funding. BCMJ $54: 448$.

Witkin, B. R., and J. W. Altschuld. 1995. Planning and Conducting Needs Assessments. Sage Publications Inc., Thousand Oaks, CA.

Wright, J., R. Williams, and J. R. Wilkinson. 1998. Development and importance of health needs assessment. BMJ 316:1310-1313. 